\title{
El régimen tributario de los dividendos en Chile como modelo para el análisis del caso colombiano
}

\author{
ViCTORIA HoYOS LONDOÑO*
}

Sumario. I. Introducción II. Sistema de Renta Atribuída III. Sistema de Renta Percibida Parcialmente Integrado. IV. Fondo de Utilidades Tributarias - FUT. Referencias.

\section{Resumen}

El presente artículo se centra en el régimen tributario de los dividendos que fue introducido en Chile por medio de la Ley 20.780 de 2014. En primer lugar, se efectuará una descripción general de los sistemas existentes (Sistema de Renta Atribuida y Sistema de Renta Percibida Parcialmente Integrado). Seguidamente, se explicará lo que ocurrirá con el Fondo de Utilidades Tributarias, FUT, que ha existido en Chile por largo tiempo, para luego sentar las consideraciones y aspectos positivos y negativos que se encuentran en dicho régimen.

Con lo anterior, se pretende identificar la conveniencia o no de adoptar para Colombia el sistema tributario que Chile propone, o la pertinencia de tomar algunos aspectos que favorezcan la tributación de los dividendos en Colombia. La metodología empleada para la elaboración del presente documento es descriptiva analítica, partiendo de las disposiciones normativas chilenas y de pronunciamientos de la Administración Tributaria de ese país, así como de fuentes académicas existentes al respecto.

\section{Introducción}

La discusión sobre la tributación de los dividendos viene cobrando una especial importancia en el actual escenario tributario colombiano. A propósito del informe final de la Comisión de Expertos para la Equidad y la Competitividad Tributaria, es preciso identificar ciertas características de otros sistemas tributarios que, como el chileno, han adoptado modelos de tributación de los dividendos que resultan atractivos y susceptibles de un análisis académico.

\footnotetext{
*Estudiante de Maestría en Derecho, con énfasis en Tributación, Universidad Externado de Colombia; Especialista en Derecho Administrativo, de la Universidad Libre de Colombia; Especialista en Derecho Tributario y Derecho Tributario Internacional de la Universidad Externado de Colombia, Abogada de la Universidad Libre. Jefe de la Oficina de Recursos Tritubarios, Secretaría Distrital de Hacienda, Bogotá, Colombia. Correo-e: vhoyos@shd.gov.co. Para citar el artículo: Hoyos, V. (2016). "El régimen tributario de los dividendos en Chile como modelo para el análisis del caso colombiano". Revista de Derecho Fiscal n. ${ }^{\circ}$ 8, Bogotá: Universidad Externado de Colombia. pp. 125-130. DOI: http://dx.doi.org/10.18601/16926722.n8.09
} 
Es preciso señalar que la importancia de que en Colombia tributen los dividendos, según la Comisión de Expertos para la Equidad y la Competitividad Tributaria, radica en que la exención sobre los mismos en materia de impuesto sobre la renta se ha convertido en uno de los factores de mayor incidencia en la baja participación de la tributación de las personas naturales, lo que, al final del día, impacta directamente la progresividad del impuesto.

Ahora bien, por estar directamente relacionado con este documento, se debe hacer mención al modelo de tributación de los dividendos que para Colombia propuso la Comisión de Expertos, el cual, a grandes rasgos, consiste en que los dividendos se incorporen en la renta ordinaria de la persona natural como un ingreso gravable. Y para atenuar la posible doble tributación que se generaría, en tanto la sociedad ya habría pagado el impuesto sobre sus utilidades, se propone que la persona natural lleve un descuento tributario del $20 \%$ en su declaración de renta.

Así las cosas, se pasará a comentar rápidamente cómo ha operado la tributación de los dividendos en Chile antes de la reforma tributaria. Luego, se identificarán las principales diferencias entre los dos sistemas (Sistema de Renta Atribuida - SRA, y Sistema de Renta Percibida Parcialmente Integrado - SRPPI) creados por la reforma y, de manera simultánea, se plantearán algunos asuntos problemáticos detectados en ese nuevo modelo de tributación de los dividendos.

En relación con la tributación de las empresas, en Chile opera el Impuesto de Primera Categoría, el cual recae sobre los ingresos provenientes de la industria, el comercio, la minería, los bienes raíces y otras actividades que involucran el uso de capital. Este im- puesto maneja tarifas progresivas que varían según el año.

También se encuentra el Impuesto de Segunda Categoría, que grava los ingresos provenientes de servicios personales de trabajadores dependientes y que, de igual manera, cuenta con tarifas progresivas. Por su parte, el Impuesto Global Complementario, que es progresivo y global, grava el total de los ingresos percibidos por personas residentes en Chile, que provengan tanto de dividendos como de sueldos y honorarios, lo que implica una percepción de ingresos combinados y generados tanto en el marco del impuesto de primera categoría como en el de segunda categoría.

En relación con los no residentes, ya sean personas naturales o jurídicas, rige el Impuesto Adicional, el cual grava los ingresos totales percibidos por los no residentes, ya sea que provengan de dividendos o de sueldos y honorarios. Por su parte, las sociedades que distribuyan dividendos a socios o accionistas no residentes en Chile están llamadas a pagar este Impuesto Adicional. Ahora bien, en relación con los dividendos, actualmente opera un impuesto de retención con derecho a crédito.

Con la reforma tributaria introducida en Chile el 29 de septiembre de 2014 (Ley 20.780 de 2014), se estableció para los contribuyentes obligados a declarar sobre la base de sus rentas efectivas según contabilidad completa la posibilidad de acogerse a alguno de los dos sistemas ya referidos, SRA y SRPPI. Se lleva por aquellos que están obligados a tributar por renta efectiva, demostrada con contabilidad fidedigna, y que no hayan obtenido autorización para llevar una contabilidad simplificada, conforme a lo dispuesto en el artículo 68 de la Ley sobre Impuesto a la Renta. 
Para efectos de elegir entre uno u otro sistema, la ley otorga a los contribuyentes que inicien actividades un plazo de dos meses para ejercer la opción (Ley 20.780 de 29 de septiembre de 2014), y a los contribuyentes que vengan desarrollando sus actividades se les permite ejercerla dentro de los tres meses siguientes al cierre del ejercicio anterior a aquel en el que se acogerán a alguno de los dos regímenes. La permanencia en cada sistema deberá ser de por lo menos cinco (5) años comerciales consecutivos, y transcurrido dicho período podrán cambiarse al régimen alternativo, en el que nuevamente se exige la permanencia de los cinco (5) años.

De acuerdo con la redacción de la ley de reforma tributaria (artículo 3), será a partir del primero de enero de 2017 que los contribuyentes podrán quedar sujetos a las disposiciones de la letra A) o B) del artículo 14 , esto es, a los dos sistemas de tributación de los dividendos establecidos. A continuación, se explicará en qué consisten los dos sistemas referidos.

\section{Sistema de Renta Atribuida}

El Sistema de Renta Atribuida (en adelante SRA) aplica a contribuyentes -entiéndase sociedades- obligados a declarar sus rentas efectivas según contabilidad completa sujetos al régimen del impuesto de primera categoría (este grava las rentas provenientes del capital, las provenientes de las empresas comerciales, industriales, mineras, servicios, entre otras) y con derecho a crédito de un $100 \%$ en los impuestos finales (en cabeza de los socios), que básicamente son el impuesto global complementario y el impuesto adicional.

De acuerdo con el artículo 2 literal b) de la reforma tributaria, por renta atribuida se entiende: [a]quella que, para efectos tributarios, corresponda total o parcialmente a los contribuyentes de los impuestos global complementario o adicional, al término del año comercial respectivo, atendido su carácter de propietario, comunero, socio o accionista de una empresa sujeta al impuesto de primera categoría conforme a las disposiciones del artículo 14, letra A) y demás normas legales, en cuanto se trate de rentas percibidas o devengadas por dicha empresa, o aquellas que le hubiesen.

Así las cosas, en el marco de dicho sistema, los socios quedarán gravados en el mismo ejercicio sobre las rentas de la empresa que les sean atribuidas en proporción a su participación. Este punto ha generado diversas reacciones de los críticos de la reforma, quienes han calificado el sistema como inconstitucional, en tanto que la atribución de la renta por parte de la sociedad al socio vulnera la capacidad contributiva del mismo. De igual manera, se ha señalado el quebrantamiento del principio de legalidad, pues se le está exigiendo al socio el pago de sus tributos por la renta imputable a la sociedad y no solo por las utilidades distribuidas bajo su calidad de tal.

Aunado a lo anterior, esto podría implicar que el socio tribute sobre rentas que aún no han ingresado a su haber. Por su parte, quienes respaldan la reforma manifiestan que el sistema de renta atribuida es uno de los que más se acerca al principio de la equidad tributaria.

Otro punto que ha generado discusión respecto de este sistema de tributación de los dividendos es el desgaste administrativo que le podría generar al ente fiscalizador chileno una solicitud de corrección del monto de la renta líquida imponible de la sociedad, pues 
ello implicaría también la corrección de la declaración del socio, de forma que él mismo deba proceder a calcular su impuesto, por la renta que finalmente le fue atribuida, tras la corrección efectuada por la sociedad.

En relación con este SRA es preciso señalar que, si bien al socio se le otorga un derecho de crédito del $100 \%$ del impuesto pagado por la sociedad, lo cierto es que el mismo opera después de imputar el $35 \%$ del impuesto global complementario sobre todas las sumas que integran su base gravable como persona física; es decir: i) la proporción de la renta líquida imponible proporcional al socio; ii) las rentas exentas del impuesto de primera categoría o las sumas que no formen parte de la renta líquida imponible, pero que se encuentren gravadas con el impuesto global complementario o adicional; iii) sumas atribuidas a la empresa en su carácter de propietaria, socia, comunera o accionista de otras empresas, comunidades o sociedades, y iv) cantidades percibidas a título de retiros o distribuciones a que tenga derecho el socio, comunero o accionista.

De otra parte, el crédito referido se calcula aplicando sobre las rentas atribuidas la tasa del impuesto de primera categoría a cargo de la empresa. A manera de ejemplo encontramos que si en virtud de la aplicación del SRA una sociedad atribuye de sus $\$ 100$ de renta total $\$ 30$ a uno de sus socios, será esta la base (por concepto de renta atribuida) sobre la que se calculará el impuesto final global complementario o adicional (35\% tarifa para 2017), y a la que deberá aplicársele de manera proporcional el crédito del $100 \%$ del impuesto de Primera Categoría -ya pagado por la sociedad y el que para el año 2017 tendrá una tarifa aproximada de $25 \%$-, por lo que el crédito a favor del socio habrá de calcularse estableciendo la proporción que el impuesto de primera categoría tiene en su renta atribuida, esto es un $7,5 \%$.

\section{Sistema de Renta Percibida Parcialmente Integrado}

El SRPPI aplica de igual manera a contribuyentes obligados a declarar sus rentas efectivas según contabilidad completa y aquellos sujetos al régimen de impuesto de primera categoría. No obstante, establece que la atribución de rentas de la sociedad al socio y el crédito deducible no es total, sino parcial.

En este sistema, el impuesto global complementario o adicional, según corresponda, se imputará únicamente a las cantidades retiradas o distribuidas a los socios, salvo que se trate de ingresos no constitutivos de renta o de devoluciones del capital. Lo que se traduce en que el socio tributa por renta percibida que, de acuerdo con el numeral 3 del artículo 2 de la Ley de Impuesto sobre la Renta, es aquella que ha ingresado materialmente al patrimonio de una persona.

El crédito parcial al que tienen derecho los socios por sus distribuciones es el que resulte de aplicar a la renta percibida el $65 \%$ del monto pagado por la sociedad por impuesto de primera categoría durante el año comercial respectivo. Véase, a manera de ejemplo, que si la sociedad pagó un impuesto de primera categoría a una tasa del $27 \%$ (máxima tasa a la que se llegará en 2018), el socio podrá usar como crédito, al momento de pagar su impuesto global complementario, hasta un 65\% (Ley 20.780 de 2014 artículo 3, literal iii. de la letra a. numeral 9) del impuesto pagado por la sociedad, esto es, $17,55 \%$. El $35 \%$ restante hará las veces de restitución del 
impuesto de primera categoría a cargo del socio o accionista, quien finalmente asumirá una tasa final de impuesto post-retiro de utilidades de $44,45 \%$.

Este sistema no ha generado grandes reacciones, dada su similitud con el que actualmente rige para la tributación de los dividendos en Chile, el cual, como se señaló en la parte primera de este documento, también cuenta con un crédito fiscal en favor del socio, quien en últimas tributa al momento de la distribución.

En relación con los contribuyentes del impuesto adicional, habrá de precisar que su tasa efectiva de tributación también será del 44,45\%, salvo que el contribuyente sea residente de un país con el que Chile haya suscrito un CDI, en cuyo caso se mantiene la integración total y no parcial del Impuesto de Primera Categoría y del Impuesto Adicional. En este caso y según lo anterior, la tributación final será del $35 \%$, tarifa establecida como límite del crédito admisible en Chile por los impuestos pagados en países extranjeros (Ley 20.780 de 2014, art. 41.c. n. ${ }^{\circ}$ 1).

\section{Fondo de Utilidades Tributarias - FUT}

Para finalizar, es importante hacer referencia al Fondo de Utilidades Tributarias -FUT-, que comprende aquellas utilidades que se generaron en la sociedad pero que, no habiéndose retirado o distribuido a los socios, nunca conformaron la base imponible del impuesto global complementario. Dicho FUT ha sido tratado como un mecanismo de diferimiento de los impuestos finales, pues estas utilidades retenidas solamente tributan al momento de su distribución o retiro a los socios, instante en el cual se cuenta con un derecho de crédito equivalente al monto del impuesto de primera categoría ya pagado por la sociedad $(20 \%)$.

En el marco de la reforma tributaria del año 2014, las sociedades podrán mantener el tratamiento tributario del FUT histórico, de acuerdo con la ley anterior, hasta el 31 de diciembre de 2016 (Ley 20.780 de 2014, artículo 3 literal i. letra b). A partir del primero de enero de 2017, las sociedades deben ejercer su derecho de opción por uno de los dos sistemas ya explicados y, en este orden de ideas, en caso de que las sociedades conserven su FUT a 31 de diciembre de 2016, todas las cantidades retiradas que excedan el orden de imputación previsto en ambos regímenes serán atribuibles al FUT histórico, lo que significa que el FUT está en el último orden de imputación. Solo durante el año 2015, los retiros del FUT histórico tuvieron una tasa del 32\% (Ley 20.780 de 2014, artículo 3 numeral 4 después de literal i.) con derecho a crédito por los impuestos pagados.

Ahora bien, partiendo de que el FUT se define como el fondo y registro de utilidades pendientes de tributación, los efectos que la reforma genera en el mismo lo convierten en un FUT histórico, en tanto las sociedades, en el marco de los dos sistemas creados por la reforma, no podrán continuar reteniendo utilidades bajo la premisa del diferimiento de impuestos finales. Bajo estas consideraciones, las sociedades deberán mantener el FUT histórico como registro al que se deberán imputar los retiros paulatinos hasta su agotamiento.

De esta manera, es posible concluir que el sistema de tributación de los dividendos adoptado en Chile tras la reforma tributaria del 2014 ha sido tan polémico como la medida de gravar los dividendos que actualmente se propone en Colombia. No obstante, el modelo chileno constituye un 
referente importante bajo el esquema de transparencia fiscal que se plantea a través del SRA y por medio de la eliminación o el alivio de la doble tributación, al hacer uso de los créditos fiscales. La doble imposición referida habrá de analizarse dependiendo de si la renta producida por la sociedad durante su actividad económica se considera un mismo objeto imponible respecto del socio y la sociedad.

\section{Referencias}

\section{Normativas}

Ley 20.780 de 29 de septiembre de 2014.

\section{Doctrinales}

Comisión de Expertos para la Equidad y la Competitividad Tributaria, Informe Final presentado al Ministro de Hacienda y Crédito Público, diciembre de 2015. 